\section{HÁBITAT POPULAR Y MERCADO LABORAL: EL DESARROLLO URBANO DESIGUAL DE LA CIUDAD DE EL ALTO (BOLIVIA) ${ }^{1}$}

Mariela Paula Díaz

\section{Resumen}

El Alto generalmente es descripto como un cinturón homogéneo de pobreza y de población de origen aymara. Sólo se encuentran afirmaciones incipientes, con escasa evidencia empírica sistematizada, sobre el desarrollo urbano desigual (y combinado) de la ciudad de El Alto. De aquí la pertinencia de esta investigación cuyo objetivo es analizar la inserción de los migrantes rurales en dos barrios de la ciudad de El Alto: en la zona periférica "El Porvenir I" y en el área céntrica 16 de Julio, en el período que comprende el inicio del neoliberalismo en el país (1985) hasta el año 2012.

\section{POPULAR HABITAT AND LABOR MARKET: UNEQUAL URBAN DEVELOPMENT IN EL ALTO (BOLIVIA) ${ }^{1}$}

\author{
Mariela Paula Diaz²
}

\section{Abstract}

El Alto is generally described as a homogeneous area of poverty with a population of Aymara origin. There is only preliminary information, with little systematized empirical evidence, about the unequal (and combined) urban development of the city. Hence the relevance of this research, which is intended to explore the incorporation of rural migrants into two neighborhoods of the city: "El Porvenir I", located in the peripheral area of the city, and "16 de Julio", located in the downtown area of El Alto. This research analyzes the period from the adoption of neoliberalism (1985) to 2012. 
En primer lugar, se indaga sobre el acceso a la ciudad en relación a la calidad de la vivienda y la provisión de los servicios públicos domiciliarios. En segundo lugar, su inserción en el mercado laboral con el fin de abordar la problemática del desarrollo urbano desigual que se vislumbra en la periferia de El Alto.

Una parte de la información fue obtenida mediante entrevistas semi-estructuradas a informantes clave y a los residentes de la ciudad; a través de la aplicación de una encuesta (muestreo estratégico no probabilístico) en los barrios bajo estudio, donde fueron seleccionados en total 100 hogares.

\section{PALABRAS CLAVES: MIGRACIÓN RURAL; DESARROLLO URBANO DESIGUAL; INFORMALIDAD LABORAL}

Recibido: 08-09-2014

Aceptado: 09-09-2015

1 Este artículo presenta parte de los resultados de la tesis doctoral de la autora.

2 Argentina. Licenciada en Sociología en la Facultad de Ciencias Sociales de la Universidad de Buenos Aires (UBA). Doctora en Ciencias Sociales de la Universidad de Buenos Aires y becaria postdoctoral del CONICET en el Instituto Multidisciplinario de Historia y Ciencias Humanas (IMHICIHU). Docente de la Universidad de Buenos Aires. Correo electrónico: madidip@gmail.com
In the first place, this research examines the access to the city in relation to the quality of dwellings and the provision of public domiciliary services. In second place, the incorporation into the labor market is analyzed in order to address the issues regarding the unequal urban development in the outskirts of El Alto.

Part of the information was collected through semi-structured interviews with key actors and inhabitants of the city. Other information was collected through the implementation of a survey (non-probabilistic strategic sampling) that interviewed 100 households located in the case study neighborhoods.

KEYWORDS: RURAL MIGRATION; UNEQUAL URBAN DVELOPMENT; INFORMAL LABOR.

Received: 08-09-2014

Accepted: 09-09-2015

1 This paper is based on the dissertation conducted by the author.

2 Argentina. BA in Sociology, Faculty of Social Sciences at the University of Buenos Aires. PhD in Social Sciences, University of Buenos Aires and CONICET postdoctoral fellow at the Multidisciplinary Institute for History and Human Sciences (IMHICIHU). Professor, University of Buenos Aires. Email: madidip@gmail.com 


\section{Introducción}

Para fines del siglo XIX y principios del siglo XX, gran parte del territorio alteño estaba concentrado en manos de latifundistas. En el altiplano norte, donde se asienta El Alto, a diferencia de otras regiones de Bolivia, las haciendas se erigieron sobre los territorios de las comunidades indígenas (ayllus) donde cada familia cultivaba su tierra y existían lugares de uso común para sembrar, es decir, se presentaba la combinación de una tenencia (posesión) privada o familiar de espacios de tierra cultivable y la propiedad comunal ${ }^{3}$. Las comunidades indígenas originarias que se hallaban en El Alto pertenecían fundamentalmente a la cultura aymara, esta característica como se analizará luego se mantiene en la actualidad.

Posteriormente, sobre la base de dichas haciendas se asentaron la mayoría de los barrios alteños. Las iniciativas de loteamientos de terrenos de los grandes propietarios iniciadas en los años 40, se aceleraron post-Revolución de 1952 y dieron lugar a un conjunto de barrios informales dispersos, sin dotación de servicios y criterios urbanísticos ni puntos de articulación urbana. De este modo, los servicios tales como agua, energía eléctrica, alcantarillado, etc., se estimaban que serían

3 Albo, 2006; Ballivián, 2009; Choque Quispe y Enríquez, 2009; Quispe Villca, 2004. provistos luego de una primera fase de parcelación especulativa y la simultánea segunda fase de edificación. Este proceso de loteamiento barato e informal permitió el asentamiento de los sectores populares quienes autoconstruyeron como una estrategia de acceso a la vivienda propia.

No sólo fueron los grandes terratenientes los que vendieron parcelas sin servicios, sino también los campesinos acomodados o medios, creando un "caos urbano" de gran magnitud, por fuera de todo tipo de planificación estatal ${ }^{4}$. Cabe destacar que en la década de 1950, por presión popular y la presencia de milicias obreras y campesinas, la Reforma Agraria se concretó en El Alto con la expropiación de la hacienda El Tejar, que ocupaba toda la zona de la Ceja (su actual centro cívico y comercial), y bajo el lema "la tierra es de quien la trabaja", se entregaron pequeñas parcelas a los campesinos. No obstante, una minoría de campesinos acomodados compró a bajo precio las parcelas de sus ex comunarios y mediante un proceso de loteamiento informal se formaron algunos de los barrios de El Alto. Además, a partir de la década del 50 y hasta fines de los años 80, una minoría de barrios de El Alto fueron creados por los programas estatales de vivienda y, los consejos de viviendas sectoriales, destinados a los aportantes (asalariados formales) del sistema. Estas políticas sectoriales y limitadas

4 Indaburu, 2004. 
de vivienda se mantuvieron en un periodo amplio en el tiempo, donde se sucedieron gobiernos democráticos (1952-1964) y principalmente de facto (1964-1982) .

La conformación de El Alto fue parte del proceso de metropolización y consolidación urbana de La Paz. Por lo tanto, se configuró como apéndice del proceso de urbanización de dicha ciudad y se le asignó funciones de acuerdo a las necesidades urbanas de ésta ${ }^{6}$. Esto se debió, en parte, a los limitantes de relieve que presenta el valle donde se ubica la ciudad de La Paz, convertida en la sede de gobierno post guerra civil entre liberales y conservadores (en 1899). En otras palabras, para comprender la conformación de El Alto es necesario ligarla con el crecimiento de la ciudad de La Paz y los limitantes del terreno que posee el valle donde se asienta. En un primer momento, se constituyó en un lugar alternativo de residencia, luego, a partir de los años 80, El Alto recibió el desborde poblacional de las laderas de la hoyada de La Paz, y se convirtió en el primer polo de atracción de las nuevas migraciones que se produjeron en

5 Desde 1952 a 1964 gobernó democráticamente el Movimiento Nacionalista Revolucionario (MNR). Luego desde 1964 hasta prácticamente el año 1982 se sucedieron diversos gobiernos de facto. En octubre de 1982 se instauró el periodo democrático con la asunción de Siles Suazo de la UDP (Unión Democrática Popular), régimen político que rige hasta la actualidad.

6 Para principios del siglo XX, la infraestructura y los equipamientos urbanos se construyeron cerca de la red interregional y ferroviaria existente en la zona de la Ceja. el país producto de la aplicación de las medidas neoliberales.

En el contexto de la Revolución de 1952, El Alto se consolidó como un barrio periférico de la ciudad de La Paz y cumplía la función de "dormitorio obrero", mientras La Paz se organizaba como la fuente laboral de sus habitantes. Luego, se convirtió en la capital de la cuarta sección de la Provincia Murillo ${ }^{7}$ del departamento de La Paz, es decir en municipio autónomo, el 6 de marzo de 1985. Finalmente, el 26 de septiembre de 1988 fue reconocida por el Congreso Nacional su estatus de ciudad. El crecimiento más fuerte de esta ciudad (y el más alto de Sudamérica) se registró en el período intercensal 1976-1992 (la tasa de crecimiento llegó al 9.2\%) ${ }^{8}$, por varios factores económicos y sociales. En primer lugar, las transformaciones neoliberales plasmadas en el Decreto $N^{\circ} 21060$ bajo el gobierno de Paz Estenssoro del mes de agosto de 1985 provocaron las oleadas migratorias de las consideradas "víctimas del sistema", lo que dio impulso al proceso de urbanización del país. Este vertiginoso crecimiento de El Alto se sucedió

7 La Provincia de Murillo está dividida en cinco secciones municipales: la sección capital La Paz, la primera sección Palca, la segunda sección Mecapaca, la tercera sección Achocalla, y por último el Municipio de El Alto.

8 Esa tasa fue ampliamente superior a las tasas de crecimiento de las principales ciudades del eje central del país. Para el mismo período (1976-1992), la tasa de crecimiento anual de La Paz fue de 1,8\%, de Cochabamba $4,2 \%$ y de Santa Cruz 6,4 \% (Garfías y Mazurek, 2005). 
especialmente de manera informal, espontánea y por fuera de toda planificación estatal ${ }^{9}$.

De este modo, los relocalizados mineros y fabriles, y los pobladores rurales del Altiplano Norte (producto de las sequías en tierras bajas e inundaciones en zonas montañosas por efecto del Niño en los años 1982-83, y la crisis agraria de 1985 debido a la apertura económica, y el problema estructural del minifundio ${ }^{10}$ ), se dirigieron a la ciudad de El Alto, y a las zonas de cultivo de hoja de coca, como en el Chapare, en el norte del departamento de Cochabamba ${ }^{11}$. La relocalización minera ocurrió por el cierre de las empresas mineras del Estado en el marco de la política de reducción de gasto estatal y de desplome del precio del estaño. Por ejemplo, la COMIBOL (Corporación Minera del Estado) despidió a más de 30.000 obreros. Lo mismo ocurrió en el sector fabril, que por la liberalización de la economía, no pudo competir con los productos importados, los cuales se vieron favorecidos también en materia arancelaria. Por consiguiente, el costo social de estas medidas se

9 Según el Censo 2012, El Alto (con 843.934 habitantes) es considerada la segunda ciudad más poblada del país, luego de Santa Cruz (con 1.453.549 habitantes).

10 Las parcelas entregadas a los campesinos a partir de la Reforma Agraria de 1953 se vieron constantemente subdividas debido al sistema de herencia de la sociedad aymara (que permite la división de la propiedad entre los hijos), lo que dio lugar al minifundio. Actualmente denominados "surcofundios", parcelas más pequeñas aún.

11 Do Alto, 2007. tradujo en el incremento del desempleo y de los niveles de pobreza, lo que obligó a los campesinos empobrecidos y a los relocalizados a migrar a las ciudades para dedicarse a otras actividades dentro de una economía informal y precarizada ${ }^{12}$.

Cabe señalar que las medidas neoliberales pudieron ser implementadas luego de haber previamente derrotado las tres últimas jornadas de lucha en la década de 1980, protagonizadas por la Central Obrera Boliviana (COB) y hegemonizada por los trabajadores mineros, con el apoyo de la FEJUVE (Federación de Juntas Vecinales) de El Alto ${ }^{13}$. Esto demuestra que las luchas sociales no son un factor subjetivo externo al proceso de urbanización y a las transformaciones socio-territoriales, por el contrario, hay una relación dialéctica o de mutua interacción entre ambos elementos (objetivos y subjetivos) $)^{14}$.

Entre otros factores del crecimiento urbano de El Alto, se encuentran la construcción de la autopista La Paz-El Alto en los años 70 que fortaleció

\section{Klein, 2002}

13 La primera, fueron las jornadas de huelga general de marzo de 1985; la segunda, la huelga general en septiembre de 1985 en rechazo al Decreto 21060; y por último, la Marcha por la Vida y la Dignidad en agosto de 1986 aplastada en el cerco militar en Calamarca, cerrándose así el ciclo de resistencia minera (García Linera, 2008).

14 Harvey, 2012. 
la conexión vial entre ambas ${ }^{15}$, la alta tasa de natalidad de la población y el elevado índice de fecundidad de las mujeres (aproximadamente 4,2 hijos por mujer) ${ }^{16}$. En la década del 90, fue declarada "ciudad en emergencia" por el elevado crecimiento demográfico y las deficiencias en materia de servicios básicos. En consecuencia, El Alto generalmente es descripto como como el enclave más pobre de la región metropolitana de La Paz ${ }^{17}$ y un espacio "racializado" (el otro étnico) que posee una baja provisión de infraestructura básica en relación a $\mathrm{La} \mathrm{Paz}^{18}$.

Si bien esta descripción a nivel macro tiene asidero, cuando se combinan diferentes escalas de análisis, una macro (urbana) y una micro (barrial) se puede dar cuenta de la diferenciación socio-espacial y del desarrollo urbano desigual y combinado que

15 Bajo el gobierno dictatorial del Gral. Hugo Bánzer, se produjo la expulsión de cientos de familias de La Paz para lograr la construcción de la autopista "El Alto- La Paz" en los años 70. En este caso, se ejecutó un plan de vivienda para el asentamiento de esas familias expulsadas, que dio lugar al origen del barrio Villa Adela, situado en El Alto.

16 Nuñez Villalba, 2011.

17 Según las últimas cifras disponibles del Censo Nacional de Población y Vivienda de Bolivia, desde el enfoque de NBI, la población pobre en la ciudad de El Alto representaba al 66,9\% en el año 2001, que superaba al país en su conjunto $(58,5 \%)$. En cambio en la ciudad de La Paz el porcentaje que correspondía a la población pobre era significativamente menor (34,5\%). Por el momento no hay información disponible del Censo 2012, no obstante, brinda un estimativo de la situación de pobreza existente

18 Gozálvez, 1996; Torrico Adad, 2004; Guaygua, 2011 y Arbona, 2008. presenta la ciudad. Respecto a este punto, sólo se encuentran afirmaciones incipientes, con escasa evidencia empírica sistematizada ${ }^{19}$.

Parafraseando a Harvey ${ }^{20}$, el concepto "desarrollo urbano desigual y combinado" alude a la incesante acumulación y concentración del capital en espacios reducidos, e implica la combinación entre lo más desarrollado de la técnica con lo más tradicional o arcaico. De este modo, la concentración en el espacio de los hombres, su infraestructura urbana, y equipamientos comunitarios tiende a aumentar el precio del suelo, y configura los lugares céntricos y consolidados (relativos) de la ciudad. En consecuencia, ciertas zonas (periféricas) que no otorgan al capital las condiciones generales de valorización permanecen inexplotadas o al margen de los "beneficios" de la economía de aglomeración,

19 Pereira Morató, 2009 y Mazurek, 2009.

20 Harvey, 2004. 
generando diversas situaciones de penurias ${ }^{21}$. Por lo tanto, este concepto se vincula también con un rasgo particular de la urbanización latinoamericana, que es la deficiente provisión de los valores de uso colectivo y la presencia de formas-no mercantiles/pre capitalistas-de producción y de socialización del consumo. Cabe destacar que este análisis se inscribe en el estudio mayor de la dependencia y de la acumulación del capital periférico que se asienta en régimen de salarios bajos ${ }^{22}$. Además, este concepto es de utilidad para comprender la dinámica urbana en su doble dimensión: la configuración territorial o el hábitat, y la dinámica social, es decir, el habitar, lo vivido y, las estrategias de inserción y apropiación de la ciudad ${ }^{23}$.

La primera dimensión hace referencia a las oportunidades diferenciales que ofrece la ciudad ligada a la distribución espacial desigual de los servicios públicos domiciliarios ${ }^{24}$ (y de mantenimiento urbano ${ }^{25}$ ), de infraestructura ${ }^{26}$, de equipamientos comunitarios ${ }^{27}$ y del servicio de transporte público, condición de posibilidad

21 Topalov, 1979.

22 Jaramillo y Cuervo, 1993; Pradilla, 1983.

23 Groisman y Suárez, 2010; PNUD, 2009.

24 Es decir, la conexión a la red de agua potable, acceso a la red de gas natural domiciliario, conexión al alcantarillado sanitario 0 a la red cloacal, y a la red eléctrica.

25 La recolección de residuos sólidos.

26 Tales como el alcantarillado pluvial o desagüe pluvial, el alumbrado público, el pavimentado y las aceras.

27 Equipamientos de salud, educación, culturales. de la existencia de rentas diferenciales en el suelo urbano. Esto último alude a las condiciones del hábitat que incluye las características de la vivienda y de contexto urbano (vecindario) ${ }^{28}$. Al mismo tiempo, teniendo en cuenta la segunda dimensión señalada, es importante analizar concretamente la relación existente entre el tipo de hábitat que define a cada barrio en cuestión, las prácticas cotidianas desarrolladas por los habitantes, la posición y las estrategias de los hogares de migrantes en el mercado de trabajo y en el de tierra/vivienda, los cuales pueden adoptar múltiples vinculaciones entre si $^{29}$.

\section{Metodología y características generales de los barrios bajo análisis}

Para la elaboración del presente estudio se aplicó una encuesta a miembros de 50 hogares (en total

28 Cabe destacar que solamente desde una "utilidad" metodológica se "separa" la vivienda del entorno urbano, ya que se adhiere a una concepción amplia de vivienda como hábitat o medio ambiente (Yujnovsky, 1984). 
100 hogares $)^{30}$ en dos barrios de la ciudad de El Alto. Para la implementación de la misma se utilizó un muestreo estratégico (no probabilístico) donde el procedimiento de selección muestral concluye cuando se llega a la saturación teórica. Si bien la muestra no es representativa de la ciudad de El Alto y de los espacios habitados, cada lugar en el que se aplicó la encuesta representa un tipo de hábitat característico de dicha ciudad ${ }^{31}$. Además, una parte de la información fue obtenida mediante observación directa, relevamiento in situ y entrevistas semi-estructuradas en profundidad a informantes-clave y a los residentes de dicha ciudad.

En general se indagó sobre la situación de la vivienda y la inserción laboral de los hogares en

30 En total se relevó información de 298 miembros de hogares. 31 Di Virgilio, 2008. los barrios El Porvenir I ${ }^{32}$ y 16 de Julio (tercera sección ${ }^{33}$ que exhiben diferentes grados se consolidación urbana. El primero se encuentra en el Distrito 7 ubicado en el sector noroeste de la periferia de la ciudad de El Alto y se fundó el 2 de febrero de 1999. En cambio, 16 de Julio, es un barrio céntrico y antiguo, se encuentra en el Distrito 6 y se creó el 16 de julio de $1944^{34}$. Según información del Censo $2001^{35}$, la densidad más alta se encuentra en el Distrito 6 con 12.467 habitantes por km2 y la más baja en el Distrito 7 con 341 habitantes por $\mathrm{km} 2$. Este último Distrito es considerado el segundo más extenso de El Alto y el que menos población tiene, constituyéndose así en un área periférica en proceso de expansión ${ }^{36}$.

32 A lo largo de este trabajo, este barrio, para abreviar, se lo denomina directamente El Porvenir.

33 El 23 de noviembre de 1985, durante la presidencia de Siles Suazo de la Unión Democrática Popular, el barrio 16 de Julio fue dividido en tres secciones. Esto ocurrió en un momento de crisis política y económica con desabastecimiento de los alimentos de primera necesidad y con una inflación galopante.

34 La ciudad de El Alto está compuesta por catorce distritos, de los cuales diez son urbanos (los distritos del 1 al 8,12 y 14) y cuatro son rurales $(9,10,11$ y 13). Cada distrito integra dentro de sí a un conjunto de barrios.

35 Por el momento no hay información disponible a esta escala de análisis según el Censo 2012. No obstante, es un parámetro general de la situación que caracteriza a ambos barrios bajo estudio.

36 Quispe, Tonconi y Canaviri, 2011. 


\section{FIGURA 1. LA CIUDAD DE EL ALTO Y SUS 14 DISTRITOS}

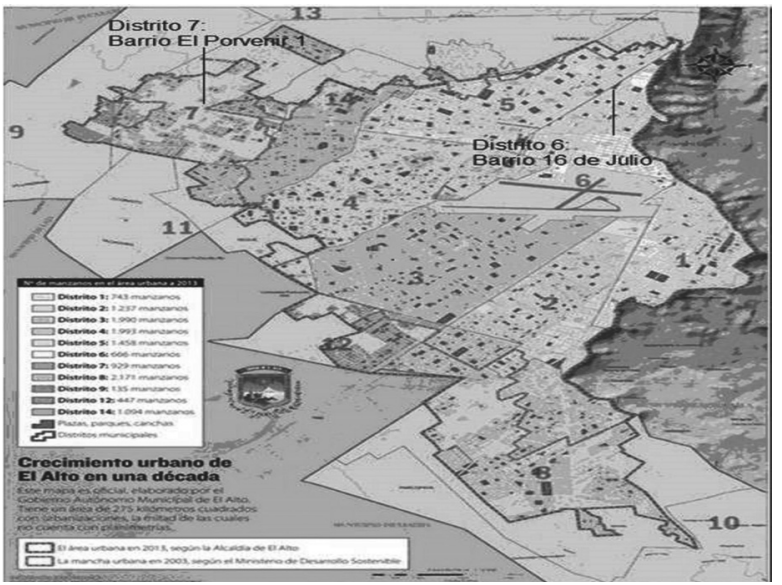

Fuente: GAMEA, 2013

Según el Censo 2001, la tercera sección del barrio 16 de Julio contaba con una población de 8.822 habitantes y para el 2012 se estimó que ascendía a 15.000 personas. Por el momento no se tiene información del último Censo respecto a esta escala de análisis. En cambio, sobre El Porvenir no se encuentran datos disponibles del Censo 2001 ya que era un barrio muy reciente, y había un estimativo poblacional como "zona San Roque" que agrupaba a varios barrios del Distrito
7. Gracias a la información brindada por la ONG SUMAJ HUASI-Para la vivienda saludable se pudo evaluar que hacia el año 2011 había 450 lotes, de los cuales 350 estaban construidos, y el número de familias que vivían en forma permanente era alrededor de 150. Por tal motivo, es considerado un "barrio de engorde", ya que muchos mantienen sus predios desabitados para luego vender o habitar cuando se establezcan todos los servicios básicos; mientras tanto residen en las zonas más céntricas de la ciudad. A partir de la encuesta aplicada en el año 2012, se pudo calcular que el promedio de miembros por familia es de 4,8. Por lo tanto, aproximadamente son 720 personas las que residen en forma permanente en el barrio, lo que evidencia una densidad poblacional mucho menor en comparación al barrio céntrico.

Por otra parte, la conformación de estos barrios sucedió en dos momentos económicos, políticos y sociales distintos. En la década de 1950, la urbanización del país se aceleró bajo el período de Capitalismo de Estado donde se desarrolló la política de industrialización por sustitución de importaciones y se aplicaron diversas reformas políticas y sociales, que entre otros, eliminó el pongueaje (forma de esclavitud en las haciendas) ${ }^{37}$ y la restricción que prohibía la entrada de la

37 La práctica del pongueaje fue formalmente proscripta en 1945 por el gobierno de Villarroel, pero en la práctica estuvo vigente otros 7 años (Dunkerley, 2003).

revista invi № 85 / Noviembre 2015 / Volumen № 30: 111-146 119 
población indígena a ciertas calles céntricas y plazas de La Paz. En cambio, hacia mediados de los años 80, bajo los gobiernos democráticos neoliberales, el crecimiento poblacional en las áreas urbanas y la migración campo-ciudad, fue una consecuencia de la política de desindustrialización (relativa), de la apertura económica y de la liberalización de la economía ${ }^{38}$.

Por consiguiente, el objetivo de este artículo es analizar el tipo de hábitat que define a los barrios El Porvenir y 16 de Julio y, qué relación puede hallarse con la posición de los hogares en el mercado de trabajo y en el de vivienda/tierra. También, es relevante analizar las relaciones entre las estrategias de acceso al hábitat y laborales de los hogares de migrantes con el tipo o condiciones estructurales del hábitat según su localización centro-periferia. Entonces, ies el lugar de origen (la condición migratoria) de la población lo que permite explicar las estrategias de acceso al hábitat y laborales, o las mismas dependen a su vez de otros determinantes de índole estructural?

Es necesario aclarar que en El Porvenir predominan los hogares con adultos nacidos en el campo (94\%), de los 50 hogares encuestados, sólo tres no

38 Pese a la distancia temporal, ya que El Porvenir se constituyó hacia fines de los años 90 y el barrio 16 de Julio hacia mediados de los años 40 , fue el loteamiento informal sin provisión de servicios básicos ni infraestructura urbana, lo que permitió el acceso de los sectores populares y migrantes de las comunidades rurales. son migrantes del campo. Mientras en el barrio céntrico imperan los hogares con adultos nacidos en la ciudad de El Alto o La Paz (60\%). Asimismo, según la información brindada por la encuesta del año 2012, el barrio periférico posee una estructura poblacional más joven que el barrio 16 de Julio (el 55\% del total de los miembros del hogar tiene menos de 20 años, mientras en 16 de Julio alcanza al $37,6 \%)$.

Con respecto a la autoidentificación de los miembros del hogar de 15 años y más, en el barrio periférico el $88,1 \%$ se autoidentifica con el pueblo aymara, cuyo porcentaje casi duplica al que corresponde a la zona 16 de Julio $(53,5 \%)$, y se asemeja al que corresponde a El Alto en su conjunto, según el último Censo (81,8\%).Esta cuestión diferencial según barrio puede relacionarse con el lugar de nacimiento o la condición migratoria de los mismos. Mientras en El Porvenir el 76,2\% de los miembros del hogar de 15 años y más nació en comunidades rurales de las provincias del departamento de La Paz y el 21,7\% en las ciudades de El Alto o La Paz, en 16 de Julio el 77,4\% de su población nació en dichas ciudades y sólo el 16,8\% en una comunidad rural. Si se analiza según grupos de edad, 
se observa que a partir de los 20 años prepondera en la zona periférica la población oriunda del campo $^{39}$.

Por el contrario, en el barrio céntrico, en el grupo de edad de 20 a 39 años y de 40 a 64 años predomina la población nacida en las ciudades de La Paz o El Alto40. Sin embargo, en el grupo poblacional de 65 años y más, el 50\% de la misma provenía de las comunidades rurales, lo que denota que en sus orígenes recibió un contingente de migrantes de origen rural.

En síntesis, El Alto es llamada la "ciudad aymara" que es uno de los rasgos que permanece pese al proceso de urbanización y metropolización. También es considerada una ciudad joven y de migrantes por su reciente conformación y por la composición de su población. Sin embargo, se destaca una distribución espacial desigual de la cultura aymara y de la población migrante,

39 Según los datos de la encuesta, la población migrante representa un $84,1 \%$ en la franja de edad de 20 a 39 años, un $92,3 \%$ entre los 40 y 64 años, y un $85,7 \%$ en el grupo de 65 años y más.

40 La población nacida en las ciudades de El Alto y La Paz representa un $86,3 \%$ en el grupo de edad de 20 a 39 años y un $58 \%$ en la franja de los 40 a 64 años, y los nacidos en el ámbito rural ascienden de $6,8 \%$ a $36 \%$ respectivamente así como de la estructura poblacional joven en la ciudad respecto a la situación de localización centro-periferia.

\section{La situación de la vivienda actual y las estrategias de acceso al hábitat}

En primer lugar, como ocurre en la ciudad de El Alto, el tipo de vivienda que predomina en ambos barrios es la casa. Con respecto a la situación de tenencia de la vivienda, en el barrio periférico el 90\% del total de los hogares son propietarios del terreno, lo que supera al porcentaje que se encuentra en la ciudad de El Alto $(68,8 \%)$ y le sigue la figura del cuidador $(8 \%)^{41}$. En el barrio 16 de Julio el $58 \%$ es propietario y el $28 \%$ alquila o se encuentra en anticresis ${ }^{42}$. En ambos casos, el tercer lugar lo ocupa la categoría "ocupación de

41 El cuidador de la casa no recibe a cambio un sueldo o bonificación económica, generalmente son familiares cercanos a los propietarios de la vivienda.

42 El contrato anticrético consiste en la entrega de un inmueble a un acreedor para que lo ocupe por un tiempo determinado. Cumplido el plazo, el acreedor debe restituir el bien a cambio de la devolución del monto de dinero entregado al inicio de contrato. Esta modalidad es usada mayoritariamente por los sectores medios y altos (Salazar Antequera, 2001).

revista invi № 85 / Noviembre 2015 / Volumen № 30: 111-146 121 
hecho, por cesión o préstamo" con el 2\% y el $8 \%$ respectivamente.

Entonces, en El Porvenir y 16 de Julio preponderan los propietarios de la vivienda; sin embargo, en este último, los que migraron hace más de 30 años pudieron acceder a un terreno propio, ya que era más económico que un lote en La Paz y en esos momentos era considerado una zona periférica de aquella ciudad. En la actualidad existe un porcentaje significativo de inquilinos que es producto en parte de su consolidación urbana "relativa" dada por su mayor densidad poblacional y edilicia, su nivel de servicios públicos, infraestructura urbana y equipamientos comunitarios. Además, a diferencia de El Porvenir43, constituyó el primer destino de muchos de los migrantes residentes en la ciudad.

La informalidad urbana alude a los aspectos dominiales 44 y hace referencia al tipo de inserción en el mercado de tierra/vivienda. Se define por

43 La población aymara migrante del campo se concentra en la periferia, luego de haber atravesado varias etapas migratorias previas desde su salida de la comunidad de origen. Esta cuestión, detallada en la tesis doctoral, excede a la temática de esta presentación.

44 Herzer, 2008. los propietarios que no poseen documentación que acredite esa condición (incluyendo en esta categoría a los que contestaron que aún está en trámite), los inquilinos (o los que se encuentran en una situación de anticrético) que no firmaron contrato de alquiler (o el contrato de anticrético), y por último, los ocupantes de hecho, por cesión o préstamo.

Como se analiza en la tabla 2, en ambos barrios el tipo de inserción en el mercado de vivienda/ tierra que impera es el formal, representando en El Porvenir el $76 \%$ y en el barrio 16 de Julio el $70,8 \%$. Es decir, esta inserción formal actual, en contraste con los orígenes de la conformación de ambas zonas, se debe a una política concreta del gobierno local de regularización de la situación dominial de la población de la ciudad, base sobre el cual la Alcaldía ejerce su "derecho" de cobro del impuesto al inmueble ${ }^{45}$.

45 En el caso puntual del barrio periférico (El Porvenir), el presidente de la Junta Vecinal también fue funcionario de la Alcaldía de El Alto, lo que benefició específicamente la implementación de esta política. 
TABLA 1. SITUACIÓN DE TENENCIA. TOTAL DE HOGARES DE LOS BARRIOS EL PORVENIR Y 16 DE JULIO. AÑO 2012, (EN PORCENTAJES)*

\begin{tabular}{lc|cc}
\hline & \multicolumn{3}{c}{ Nombre del Barrio } \\
Situación de tenencia & El Porvenir & 16 de Julio & Total \\
\hline Propia & 90 & 58 & 74 \\
\hline Alquilada & 0 & 24 & 12 \\
\hline Cuidador & 8 & 6 & 7 \\
\hline Anticrético & 0 & 4 & 2 \\
\hline $\begin{array}{l}\text { Ocupación de hecho, por cesión } \\
\text { o préstamo }\end{array}$ & 2 & 8 & 5 \\
\hline Total & $100(50)$ & $100(50)$ & 100 \\
\hline
\end{tabular}

Fuente: Elaboración propia según encuesta realizada en el año 2012.

TABLA 2. TIPO DE INSERCIÓN EN EL MERCADO DE TIERRA Y VIVIENDA. TOTAL DE HOGARES DE LOS BARRIOS EL PORVENIR Y 16 DE JULIO. AÑO 2012, (EN PORCENTAJES)*

\begin{tabular}{|c|c|c|c|}
\hline \multirow{2}{*}{ Nombre del Barrio } & \multicolumn{2}{|c|}{ Tipo de inserción en el mercado de tierra y vivienda } & \multirow{2}{*}{ Total } \\
\hline & Formalidad & Informalidad & \\
\hline El Porvenir & 76 & 24 & $100(50)$ \\
\hline 16 de Julio & 70,8 & 29,2 & $100(48)$ \\
\hline
\end{tabular}

* Del total de la población, se eliminaron los que correspondían a la categoría "No sabe, no contesta".

Fuente: Elaboración propia según encuesta realizada en el año 2012. 
Como se analizará más adelante, la problemática del barrio periférico es fundamentalmente la cuestión de la precariedad de su hábitat: de la vivienda en sí misma y del contexto urbano. Se ha adoptado para estudiar esta cuestión un planteo que propone, en primer término, analizar los principales elementos de la vivienda para luego integrarla con el contexto urbano de cada barrio. Para ello se estudiarán: los materiales más utilizados en los pisos, techos y paredes de la vivienda, y el alcance de los servicios públicos domiciliarios. Es decir, en este apartado y en el siguiente se hace hincapié en la dimensión urbana referida a la configuración del hábitat. Este análisis puede derivar en indicadores que permitan comprender las estrategias de acceso al hábitat y las apropiaciones urbanas específicas.

Con respecto a los materiales de construcción utilizados, en la encuesta se relevaron las categorías presentes en el Censo Nacional de Población y Vivienda del país, es decir, los predominantes en pisos, paredes y techos. No obstante, no arrojan datos significativos porque no permiten dar cuenta del estado de esos materiales, por lo tanto, sólo se incluye el "piso de tierra" como indicador relevante de la precariedad46. Esta última idea se refuerza, si se tiene en cuenta la antigüedad de las viviendas en cada barrio ${ }^{47}$.

\section{Herzer, 2008}

47 En El Porvenir predominan las viviendas de hasta 20 años (98\%), mientras en 16 de Julio éstas imperan con el $52,4 \%$ seguidas por las viviendas de más de 20 años (hasta los 80 años) con el $47,6 \%$.

\section{Material utilizado en los techos y las paredes: indicador de la práctica de autoconstrucción}

Los materiales más utilizados en los techos de la vivienda, en ambos barrios de la ciudad de El Alto son la calamina o la plancha metálica (con el 98\% en El Porvenir y el 88\% en 16 de Julio). Esto es una característica de la ciudad de El Alto, donde según el Censo 2012, el 92,1\% de los hogares construyen con esos materiales.

Cabe destacar el material más utilizado en las paredes de las viviendas, ya que de ello puede derivarse una forma particular de construcción de la vivienda. En El Porvenir es el adobe/tapial (64\%), mientras en el barrio céntrico es el ladrillo, bloque de cemento u hormigón (66\%). El adobe/tapial era lo que prevalecía en El Alto según los censos 1992 y $2001(89,4 \%$ y 77,1\% respectivamente), para ocupar en el 2012 el segundo puesto (45,5\%), luego del ladrillo/bloque de cemento/hormigón (53,8\%).

Respecto al adobe no se puede hablar de material precario ya que no se posee información sobre las condiciones del mismo (si se encuentra revocado 
o no, por ejemplo) por lo tanto es analizado como indicador de la práctica de la autoconstrucción que configura especialmente (aunque no únicamente) la estrategia de los hogares de migrantes para acceder a la vivienda propia. En El Porvenir preponderan los hogares que autoconstruyeron su vivienda (86,4\%), en el barrio 16 de Julio imperan los que no la autoconstruyeron (64,3\%). La mayoría de los hogares (de migrantes del área rural) del barrio periférico utilizó la estrategia de la autoconstrucción $(87,8 \%)$, mientras en el barrio 16 de Julio, el porcentaje es menor (46,2\%). Al mismo tiempo, entre los hogares de no migrantes residentes en este último barrio, solo autoconstruyeron su vivienda un $26,7 \%$.

Lo que sucede en el barrio periférico, no sólo es expresión de un saber práctico (colectivo y familiar) preexistente en su vida comunitaria del ámbito rural sino también un indicador económico de los menores ingresos presentes en el hogar. Por ejemplo, Antonio (58 años) oriundo del área rural que reside en El Porvenir señaló que su vivienda la autoconstruyó solo con adobe porque "es más caliente y más económico, yo no tengo plata para comprar ladrillo". Esta cuestión se refuerza cuando se analiza de dónde provino la ayuda para llevar a cabo la autoconstrucción de la vivienda. En El Porvenir los migrantes que autoconstruyeron su vivienda y recibieron ayuda, la misma provino principalmente de familiares y miembros del hogar. En cambio, en el caso del barrio 16 de Julio, predominaron los hogares de migrantes que afirmaron haber contado con ayuda de albañiles, y solo una minoría se refirió a la ayuda familiar.

Los hogares de migrantes optimizan los escasos recursos familiares comprando en la periferia donde hay una mayor cantidad de lotes baratos sin servicios. De hecho, hemos observado cómo en los días de semana por la mañana sobre todo las mujeres (ya que los hombres se encontraban trabajando fuera de la casa) colocaban a secar los bloques de adobes en los predios vacíos del barrio, que serian luego utilizados para terminar de construir su vivienda.

Además, queda manifestada la lógica de construir ciudad o las estrategias de los loteadores informales de buscar maximizar su ganancia creando urbanizaciones populares en la periferia sin la dotación correspondiente de los servicios públicos básicos48. Esto generó una tendencia a la extensión continua que produjo una estructura territorial difusa. Esta dinámica urbana provocó la emergencia las juntas vecinales como formas de autoorganización de la población para buscar solucionar sus necesidades básicas urbanas. Las mismas igualmente a principios de la década

48 Abramo, 2012 
del 2000 articularon exigencias de tipo políticoreivindicativo, lo que generó la caída presidencial de Sánchez de Lozada y luego de Carlos Mesa, dando lugar al quiebre del ciclo neoliberal.

Por lo tanto, el desarrollo urbano del barrio depende fundamentalmente del trabajo de los vecinos (quienes no sólo autoconstruyeron su vivienda sino también los componentes colectivos del hábitat, en algunos casos atravesado por el clientelismo político) y de las luchas sociales que ponen el acento en el derecho a la ciudad (como las jornadas de octubre de 2003, y la protesta de la FEJUVE de agosto de 2011) ${ }^{49}$. Entonces, si un barrio mejora es por la presión y la participación activa de la población, y no por una planificación estatal previa. De esta manera, no sólo el Estado y el mercado (especialmente el informal) "construyen ciudad" sino también (y principalmente) los sectores populares y los trabajadores. En cambio, en la actualidad, el barrio 16 de Julio al ser considerado uno de los más consolidados de El

49 Como se remarcó anteriormente, estos hechos descriptos también son ejemplos de la importancia de estudiar las transformaciones socio-territoriales y las luchas sociales en su relación dialéctica (Harvey, 2012).
Alto y contar con más recursos municipales ${ }^{50}$ es el gobierno local quien se encarga de realizar el mejoramiento de la infraestructura urbana como es el asfaltado de calles mediante el Programa de Mejoramiento de Barrios.

En resumen, la autoconstrucción de los hogares de migrantes que se concentra en la periferia, implica una estrategia de acceso al hábitat (y a la ciudad) que da como resultado un modelo de hábitat particular: viviendas con paredes de adobe, con patio adelante donde se halla generalmente una huerta y corrales para sus animales de consumo familiar, y al mismo tiempo, los predios vacíos fuera del lote de la vivienda (el espacio público) se transforman en una extensión de la vivienda, donde pastorean a sus animales y siembran todo tipo de verduras, lo que da lugar a una apropiación urbana específica con una connotación rururbana.

En otras palabras, el barrio periférico de baja consolidación urbana se articula con el desarrollo de prácticas cotidianas hibridas, actividades de indole rural llevadas a cabo especialmente por las mujeres, que forman parte de las tareas del hogar que incluyen el cuidado de los hijos. Esta cuestión

50 La sanción de la Ley de Participación Popular (1994) estableció los principios de distribución igualitaria por habitante (que actualmente se mantiene) de los recursos de coparticipación tributaria (provenientes de los ingresos nacionales) asignados y transferidos a los Departamentos a través de los municipios $(20 \%)$ y Universidades Públicas $(5 \%)$ correspondientes, buscando corregir los desequilibrios históricos entre las áreas rurales y urbanas. 
interesante alude a la dimensión dinámica señalada respecto al estudio del territorio urbano que no podrá ser desarrollada en este trabajo. En este sentido, El Porvenir está atravesando, desde fines del siglo XX, las experiencias de autoconstrucción de la vivienda y de producción social del hábitat ${ }^{51}$ que en el barrio 16 de Julio sucedieron en los inicios de su crecimiento (1950-1980). Al contrario, a mediados de los años 80, el impacto de la dolarización en el costo de la vivienda, en el precio de la tierra urbana y en el conjunto del mercado inmobiliario "empujó" a los sectores populares a desarrollar su estrategia de autoconstrucción hacia los suelos más baratos de la periferia con menor densidad poblacional y edilicia ${ }^{52}$. Esta situación es una muestra adicional del desarrollo desigual que presenta El Alto.

51 La producción social del hábitat, a diferencia de la autoconstrucción, no descansa en las unidades de tipo individual o familiar, sino en agentes sociales o en formas comunitarias, colectivas y organizadas que controlan directamente el proceso productivo, y que pueden articularse o no con los procesos de autoconstrucción (Rodríguez, Di Virgilio, Procupez, Vio, Ostuni, Mendoza y Morales, 2007).

52 Durán, Arias y Rodríguez, 2007.
Por último, la autoconstrucción de la vivienda, característica particular de las urbes latinoamericanas ${ }^{53}$, es una forma no estatal de socialización del consumo privada (no mercantil y pre-capitalista) y base de la reproducción social que está por fuera de la relacional salarial, la cual es funcional a la acumulación capitalista periférica que se asienta en un régimen de salarios bajos ${ }^{54}$. También muestra tanto las dificultades para proveer de vivienda a toda la población a través de la producción capitalista de vivienda como la imposibilidad del Estado de enfrentar el problema estructural del hábitat popular. Se estima que sólo el 15\% de las viviendas alteñas fueron construidas con una participación directa y/o indirecta del Estado, lo que expresa la proliferación de las urbanizaciones sin previa planificación estatal ${ }^{55}$.

53 Jaramillo y Cuervo, 1993; Pradilla, 1983.

54 Jaramillo y Cuervo, 1993.

55 Durán, Arias y Rodríguez, 2007. 
TABLA 3. AUTOCONSTRUCCIÓN DE LA VIVIENDA SEGÚN LUGAR DE NACIMIENTO DE LOS MIEMBROS ADULTOS DEL HOGAR. TOTAL DE HOGARES PROPIETARIOS DE SU VIVIENDA EN LOS BARRIOS EL PORVENIR Y LA 16 DE JULIO, AÑO 2012. (EN PORCENTAJES)*

\begin{tabular}{|c|c|c|c|c|}
\hline \multirow{2}{*}{ Nombre del Barrio } & & \multicolumn{2}{|c|}{ ¿Su vivienda es autoconstruida? } & \multirow{2}{*}{ Total } \\
\hline & & Sí & No & \\
\hline \multirow{3}{*}{ El Porvenir } & $\begin{array}{l}\text { Hogar con adultos } \\
\text { nacidos en campo }\end{array}$ & 87,8 & 5 & $100(41)$ \\
\hline & $\begin{array}{l}\text { Hogar sin adultos } \\
\text { nacidos en el campo }\end{array}$ & 66,3 & 33,3 & $100(3)$ \\
\hline & Total & 86,4 & 13,6 & $100(44)$ \\
\hline \multirow{3}{*}{16 de Julio } & $\begin{array}{l}\text { Hogar con adultos } \\
\text { nacidos en campo }\end{array}$ & 46,2 & 53,8 & $100(13)$ \\
\hline & $\begin{array}{l}\text { Hogar sin adultos } \\
\text { nacidos en el campo }\end{array}$ & 26,7 & 73,3 & $100(15)$ \\
\hline & Total & 35,7 & 64,3 & $100(28)$ \\
\hline
\end{tabular}

* Se eliminaron los casos que correspondían a la categoría "No saben, no contestan

Fuente: Elaboración propia según encuesta realizada en el año 2012.

\section{Precariedad de la vivienda y del vecindario}

Para poder analizar la precariedad de la vivienda, el material más utilizado en los pisos puede ser un indicador de ello. En ambos barrios predomina el cemento o ladrillo fijo (64\% en El Porvenir y
$66 \%$ en el barrio 16 de Julio). No obstante, en el barrio periférico sigue persistiendo un porcentaje significativo de pisos de tierra (22\%), que muestra su precariedad. 
TABLA 4. MATERIAL MÁS UTILIZADO EN LOS PISOS DE LAS VIVIENDAS. TOTAL DE HOGARES DE LOS BARRIOS EL PORVENIR Y 16 DE JULIO, AÑO 2012 (EN PORCENTAJES)

\begin{tabular}{l|c|c}
\hline \multirow{2}{*}{ Material más utilizado en los pisos de la vivienda } & \multicolumn{2}{c}{ Nombre del Barrio } \\
\cline { 2 - 3 } $\begin{array}{l}\text { Cerámica, baldosa, mosaico, parquet, alfombra, } \\
\text { madero o plástico }\end{array}$ & 14 & 20 \\
\hline Cemento o ladrillo fijo & 64 & 66 \\
\hline Tierra & 22 & 6 \\
\hline Piedra o empedrado & 0 & 8 \\
\hline Total & $100(50)$ & $100(50)$ \\
\hline
\end{tabular}

Fuente: Elaboración propia según encuesta realizada en el año 2012.

Este porcentaje que corresponde al piso de tierra supera al que se presenta en la ciudad de El Alto en su conjunto, ya que según el Censo 2012, ocupa el tercer lugar con $17,1 \%$, luego del cemento (57,6\%), y el machimbre o parquet (18,8\%). Para medir la precariedad de la vivienda en relación a los servicios públicos domiciliarios, en la tabla 5 se presentan los indicadores considerados más relevantes que permiten demostrar el grave problema de la precariedad de las viviendas del barrio periférico frente al barrio céntrico y antiguo. Para ello, se analiza si la vivienda posee red de gas natural domiciliario, red de agua potable y el tipo de distribución de la misma, si posee baño o sistema sanitario, con arrastre de agua o no, y el tipo de desagüe. 
TABLA 5. SITUACIÓN DE PRECARIEDAD DE LAS VIVIENDAS (EN PORCENTAJES)

\begin{tabular}{l|c|c}
\hline \multirow{2}{*}{ Indicador de precariedad } & \multicolumn{2}{c}{ Nombre del Barrio } \\
\cline { 2 - 3 } & El Porvenir & 16 de Julio \\
\hline Hogares sin gas domiciliario & 100 & 44 \\
\hline $\begin{array}{l}\text { Hogares sin distribución de agua potable } \\
\text { por cañería }\end{array}$ & 12 & 2 \\
\hline $\begin{array}{l}\text { Hogares sin baño en la vivienda } \\
\text { Hogares con baño pero sin alcantarillado } \\
\text { sanitario (o red cloacal) }\end{array}$ & 40 & 2 \\
\hline
\end{tabular}

Fuente: Elaboración propia según encuesta realizada en el año 2012.

Bajo el periodo de la globalización post-neoliberal (2006 hasta la actualidad) se desarrollaron políticas que denotaron un cierto componente "nacionalista" y "neodesarrollista" del considerado capitalismo andino ${ }^{56}$ (aunque la asociación con el capital trasnacional se salvaguardó), como la nacionalización de Yacimientos Petrolíferos Fiscales Bolivianos y del servicio de agua potable y alcantarillado sanitario. La primera fue una de las demandas más importantes de las jornadas de protesta de octubre de 2003 y de mayo-junio de 2005 que tuvieron su epicentro en la ciudad

56 García Linera, 2006. de El Alto. Entre enero y marzo de 2005 (durante la presidencia de Carlos Mesa) se desarrolló "la segunda guerra del agua" ${ }^{\text {"7t }}$ donde El Alto volvió a ser la protagonista de la lucha por la recuperación nacional de los recursos naturales "entregados" en el período neoliberal, al exigir la inmediata expulsión de la empresa trasnacional Aguas del Illimani.

Pese a los avances que ocurrieron en cuanto a la cobertura de los servicios públicos domiciliarios post-levantamiento aymara de octubre de 2003, luego del desarrollo de esta investigación, se

57 La primera se produjo en el año 2000 en Cochabamba, donde se conformó la Coordinadora del Agua y la Vida, y se logró expulsar a la trasnacional Bechtel-Aguas del Tunari, visibilizándose, de esta manera, la problemática acuífera a nivel nacional (Mamani Ramírez, 2004). 
deduce que los mismos se siguen concentrando en las áreas céntricas de mayor densidad poblacional y edilicia, dejando al margen a las áreas periféricas de la ciudad.

En el barrio El Porvenir, la precariedad de la vivienda se demuestra ampliamente, ya el 12\% de los hogares no tienen distribución de agua potable por cañería, porcentaje que supera ampliamente al que corresponde a la ciudad según el Censo $2012(1,9 \%)^{58}$. El 88\% de los hogares restantes sólo cuentan con distribución de agua por cañería en el patio de la casa, lo cual constituye un factor de riesgo sanitario. Este último rasgo de precariedad también es característico de El Alto, sólo que según el Censo 2012, la distribución de agua por cañería fuera de la vivienda pero dentro del terreno, representa el 32,4\%.

El 40\% de los hogares no tienen sistema sanitario, lo que resalta frente al que presenta la ciudad en el año $2012(21,4 \%)^{59}$. Aquellos que poseen baño (de uso exclusivo de la familia) no gozan de arrastre de agua: más del 80\% tienen desagüe a un recipiente debajo del inodoro (baños ecológicos), y el resto a un pozo ciego. Por último, el total de los hogares no poseen red de gas domiciliario y utilizan la garra-

58 De ese total, se dividen entre los que acceden mediante las piletas públicas, y a quienes les provee familiares y vecinos (cada caso representa un $6 \%$ ).

59 De este total, recurren en mayor medida a un terreno baldío o a un campo abierto $(60 \%)$ y al río $(30 \%)$.

ARTÍCULO: Hábitat popular y mercado laboral: El desarrollo urbano desigual de la ciudad de El Alto (Bolivia) / Mariela Paula Díaz fa que tiene un impacto regresivo en la economía del hogar ${ }^{60}$. En la ciudad de El Alto, el 58\% de los hogares utilizan la garrafa y sólo el 38,9\% poseen red de gas domiciliario a pesar de la "Nacionalización de YPFB" bajo el periodo post-neoliberal, y de ser el segundo país de América Latina en reservas gasíferas probadas después de Venezuela.

Esta situación se ve agravada por poseer un contexto urbano igualmente precario, con bajas inversiones en obras públicas, infraestructura, equipamientos y problemas agudos en la accesibilidad. Por ejemplo, posee calles de tierra; cuenta con las matrices de alcantarillado sanitario pero hasta la actualidad no cumple su función; las aceras sólo se hallan donde habitan los pobladores. El alumbrado público y el servicio de transporte son deficientes, este último no ingresa al barrio y a partir de las 20hs. se torna muy difícil poder salir de las áreas periféricas.

Respecto al equipamiento comunitario cuenta con su escuela, su sede social y una iglesia que por los problemas que surgieron con los vecinos mantiene sus puertas cerradas. También carece de un centro de salud, el más cercano se encuentra en la zona de San Roque a 20 minutos en movilidad.

60 El ex director de Planificación de la Alcaldía de El Alto señaló que la garrafa tiene un costo de 21,50 bolivianos ( 3,12 dólares) y que una familia tipo necesita entre dos y tres por mes. Mientras el servicio de gas domiciliario por mes posee un costo de, aproximadamente, 30 bolivianos (4,35 dólares) en forma mensual.

revista invi № 85 / Noviembre 2015 / Volumen № 30: 111-146 
La recolección de residuos, un servicio de mantenimiento urbano esencial, es defectuoso ya que actualmente sólo se gestiona por la carretera principal a Copacabana, y una vez por semana o cada dos semanas entra al barrio. Es así que se observaron calles desbordadas de basura y el río contaminado por la deficiencia del servicio, siendo un foco de enfermedades infecciosas.

En el barrio céntrico, su consolidación urbana si bien es evidentemente mayor que en las zonas periféricas, sigue siendo "relativa" ${ }^{1}$ en cuanto existen falencias estructurales por resolver, cuestión distintiva de las urbanizaciones dependientes caracterizadas por una baja provisión de valores de uso colectivo $^{62}$. En contrapartida, la recolección de residuos es diaria, el servicio de transporte funciona las $24 \mathrm{hs}$., posee sus escuelas públicas y privadas, se halla la feria más grande de Bolivia y la segunda mayor de Sudamérica; se encuentran clínicas privadas y la que es pública se localiza en el barrio colindante Los Andes a cinco minutos en movilidad. A su vez, en el 2013 gracias al Programa Mejoramiento de Barrios se cambió el enlosetado y empedrado, que tenían más de 15 años, por cemento

61 Su consolidación urbana es también "relativa" debido a que la misma es medida en "relación" a los barrios periféricos insertos en una ciudad que posee un alto porcentaje de población con $\mathrm{NBI}$.

62 Jaramillo y Cuervo, 1993. rígido. Además, ostenta una mayor cobertura de cada uno de los servicios señalados, aunque manifiesta rasgos de precariedad. En primer lugar, el $98 \%{ }^{63}$ de los hogares cuentan con red de agua potable domiciliaria, de éstos el 56,2\% tienen distribución de cañería en el cuarto donde se cocina y en el baño. El 37,5\% sólo en el patio de la casa, y el 6,2\% sólo en el baño, que constituyen rasgos de precariedad. La totalidad de los hogares tienen sistema sanitario y la mayoría es de uso exclusivo de la familia (86\%). El 98\% cuentan con red cloacal (alcantarillado sanitario), se presenta sólo un caso cuyo tipo de desagüe es a un pozo ciego. Por último, el 66\% de los hogares poseen red de gas domiciliario. No obstante, conserva un sistema de alcantarillado sanitario y de agua potable obsoleto e inadecuado a la cantidad de población que presenta el barrio, y una carencia de alcantarillado pluvial (al igual que el resto de los barrios de la ciudad de El Alto). La información presentada se sintetiza en la siguiente tipología de vivienda precaria $^{64}$ :

63 Se presentó un solo hogar que explicó que un familiar, que también es su vecino, le provee de agua.

64 Esta tipología agrupa a aquellos hogares que cumplieron al menos una de estas condiciones: sin red de gas domiciliario, sin red de agua potable, sin baño, con piso de tierra, con baño (pero sin arrastre de agua), con red de agua potable domiciliario pero con distribución por cañería sólo en el patio o en el baño de la casa. 
TABLA 6. TIPOLOGÍA DE VIVIENDA. TOTAL DE HOGARES DE LOS BARRIOS EL PORVENIR Y 16 DE JULIO. AÑO 2012 (EN PORCENTAJES)

\begin{tabular}{lc|c}
\hline \multirow{2}{*}{ Tipo de vivienda } & \multicolumn{2}{c}{ Nombre del Barrio } \\
\cline { 2 - 3 } & El Porvenir & 16 de Julio \\
\hline Vivienda precaria & 100 & 58 \\
\hline Vivienda no precaria & 0 & 42 \\
\hline Total & $100(50)$ & $100(50)$ \\
\hline
\end{tabular}

Fuente: Elaboración propia según encuesta realizada en el año 2012.

En El Porvenir, la totalidad de las viviendas de los hogares encuestados son precarias, ya que se parte de una situación estructural homogénea, caracterizada por la ausencia de gas natural a domicilio, la distribución de agua por cañería se encuentra sólo en el patio de la casa, y las viviendas que tienen baño no tienen arrastre de agua. En el barrio 16 de Julio, el 58\% de las viviendas también se hallan en una situación de precariedad. Por consiguiente, si comparamos la precariedad de las viviendas en ambos barrios, El Porvenir se define como una zona homogénea también en cuanto a las condiciones precarias de la vivienda.

De esta manera, el hábitat del barrio periférico se define por la supremacía de la formalidad urbana (respecto a la situación dominial) y una situación homogénea en cuanto a la precariedad de la vivienda y del entorno urbano. En otras palabras, la homogeneidad social interna que describe a este barrio, con fuerte predominancia de hogares de migrantes, trae consigo oportunidades desiguales de acceso a los servicios públicos, a las infraestructuras urbanas y a los equipamientos comunitarios. En el barrio 16 de Julio también se halla una preeminencia de la formalidad urbana pero con una heterogeneidad de situaciones ya que coexiste en un mismo espacio lo precario (que es lo que prevalece sin distinción migratoria) y lo no precario, aunque en un contexto urbano de mayor consolidación "relativa". La diferenciación socioespacial de los dos barrios estudiados (e incluso dentro del mismo barrio céntrico) es una muestra del desarrollo urbano desigual y combinado que presenta la ciudad de El Alto, y por ende como se planteó, de las oportunidades diferenciales de acceso a los bienes materiales de la ciudad. 


\section{Las estrategias laborales y la posición de los hogares en el mercado de trabajo}

Para describir la posición de los hogares de ambos barrios en el mercado de trabajo se analiza la ocupación principal del considerado jefe de hogar ${ }^{65}$ que en general se lo identifica con el varón adulto ${ }^{66}$. Es clave la identificación de ese miembro del hogar para definir la estructura de clase en la que se posiciona una familia. Se indagó sobre el tipo de inserción en el mercado laboral (formal e informal), y la calidad de la ocupación en relación a la inestabilidad (rasgo adicional de precariedad). Esta temática es importante ya que permitirá indagar qué relación puede hallarse entre el tipo de hábitat que caracteriza a cada barrio con la posición de los hogares en el mercado laboral, cuestión que alude a las distintas maneras de "habitar" la ciudad y a las estrategias desplegadas por los sujetos.

65 La mayoría de los jefes de hogar activos no poseen ocupaciones secundarias, por lo tanto, este análisis se centrará en la ocupación considerada como la principal.

66 El 92\% del total de los hogares de El Porvenir y un porcentaje menor, el $74 \%$ en el barrio 16 de Julio se identifica al varón como jefe de hogar.
El estudio de las estrategias laborales expresan al mismo tiempo estrategias de reproducción material de la familia. Al respecto, es importante señalar que la familia con el núcleo conyugal primario completo $^{67}$ es la que rige en ambos barrios. Dada la imposibilidad de desagregar la información en múltiples variables por la cantidad total de hogares encuestados, se aclara que en el barrio periférico el 92\% de los jefes de hogar son oriundos de las comunidades rurales, mientras en el barrio céntrico el 68\% de los jefes de hogar no son migrantes (es decir nacieron en las ciudades de El Alto o La Paz), y sólo el 32\% son migrantes. En ambos barrios, los jefes de hogar son activos, representando en el barrio de la periferia la totalidad de los hogares encuestados y en el barrio céntrico un 90\% ${ }^{68}$. También, se concentran como trabajadores por cuenta propia sin empleados a su cargo y como obreros/ empleados ${ }^{69}$.

67 Del total de los hogares en El Porvenir y 16 de Julio, el $78 \%$ y el $66 \%$ respectivamente corresponden a familias nucleares con el núcleo conyugal primario completo.

68 En el barrio 16 de Julio se presentan sólo cinco casos de jefes de hogar inactivos, de los cuales el $80 \%$ son jubilados y el $20 \%$ ama de casa (un caso).

69 En El Porvenir con el $48 \%$ y $42 \%$ respectivamente, y en el barrio 16 de Julio con el $37,8 \%$ y $28,9 \%$. Luego le siguen los pequeños patrones (con el $6 \%$ y el $11 \%$ respectivamente). A diferencia del barrio periférico, en el barrio céntrico el $6,7 \%$ de los jefes de hogar (mujeres) se insertan como empleadas domésticas. 
TABLA 7. OCUPACIÓN PRINCIPAL DE LOS JEFES DE HOGAR ACTIVOS. TOTAL DE HOGARES DE LOS BARRIOS EL PORVENIR Y 16 DE JULIO, AÑO 2012 (EN PORCENTAJES)*

\begin{tabular}{lcccccc}
\hline & \multicolumn{5}{c}{ ¿Cuál es la ocupación principal del jefe de hogar? } \\
$\begin{array}{l}\text { Nombre del } \\
\text { Barrio }\end{array}$ & $\begin{array}{c}\text { 1 Obrero o } \\
\text { Empleado }\end{array}$ & $\begin{array}{c}\text { Trabajador por cuenta } \\
\text { propia con empleados } \\
\text { a su cargo (Patrones } \\
\text { pequeños) }\end{array}$ & $\begin{array}{c}\text { Trabajador por } \\
\text { cuenta propia } \\
\text { sin empleados a } \\
\text { su cargo }\end{array}$ & $\begin{array}{c}\text { Empleada } \\
\text { doméstica }\end{array}$ & 2Ns/Nc & Total \\
\hline El Porvenir & 42 & 6 & 48 & 0 & 4 & $100(50)$ \\
\hline 16 de Julio & 28,9 & 11,1 & 37,8 & 6,7 & 15,5 & $100(45)$ \\
\hline
\end{tabular}

* Bajo la categoría "No sabe, no contesta" se agrupa a aquellos casos donde se relevó la ocupación y no la categoría ocupacional solicitada Fuente: Elaboración propia según encuesta realizada en el año 2012..

Puede observarse que los barrios bajo estudio revelan la composición socio-económica de El Alto, que según el Censo 2012, está compuesta principalmente por obreros/empleados (43\%) y trabajadores por cuenta propia sin empleados a su cargo (43,3\%). Las actividades cuentapropistas se ligan principalmenteconlosmicroemprendimientos que preponderan en la ciudad de El Alto. Son formas productivas precapitalistas, que se sustentan fundamentalmente en el trabajo familiar no asalariado, que suelen desarrollarse en un lugar dentro la misma vivienda. En otras palabras, la utilización de la vivienda no solamente como un lugar de alojamiento sino también de trabajo es una estrategia familiar de inserción en el mercado laboral.

En El Porvenir y 16 de Julio, las denominadas viviendas productivas representan un $24,5 \%$ y un $24 \%$ respectivamente. En este caso, se considera importante analizar este tipo de utilización de las viviendas vinculado a los hogares según lugar de nacimiento de los adultos, para poder relacionarlo más ampliamente con la condición migrante de los mismos, ya que puede ocurrir que el jefe de hogar no sea migrante pero sí el cónyuge, y de ahí puedan derivar ciertas prácticas en la ciudad. 
En la periferia, casi el 22\% de los hogares de migrantes afirman tener un lugar para trabajar dentro de su vivienda. En el barrio céntrico representa al 30\% de los hogares de migrantes y al 20\% de los hogares de no migrantes. Por consiguiente, puede considerarse que este porcentaje del $20 \%$ y más, en cada uno de los barrios es un dato significativo que se encuentra, en mayor medida (aunque no exclusivamente) en los hogares de migrantes de ambos barrios ${ }^{70}$. Esta estrategia laboral se vincula fundamentalmente con las condiciones estructurales de la economía alteña, donde la producción en pequeña escala de bienes y servicios de primera necesidad destinados al mercado interno son los principales generadores de empleo e ingresos de los hogares alteños ${ }^{71}$.

70 Esta actividad económica puede estar subordinada a los requerimientos de empresas tanto locales como extranjeras, lo que indica una "subsunción formal del trabajo al capital".

71 Wanderley, 2009.
Esta práctica de autoempleo se masificó a partir de los años 80 como una forma de paliar el desempleo producto de la crisis económica que vivió el país en esa década y las consecuencias sociales que trajo consigo la aplicación de las medidas neoliberales. La proliferación de las microindustrias expresa no sólo los límites del mercado laboral para absorber a la totalidad de la población sino fundamentalmente la estrategia del capital de reducir sus costos de producción ${ }^{72}$. Así como también el problema estructural de Bolivia, como país dependiente, que se basa en un patrón de crecimiento económico centrado en el sector primario exportador, que no genera puestos de trabajo suficientes para el conjunto de la población ${ }^{73}$.

72 No se parte de una perspectiva dicotómica de análisis, como explicó Portes (2004), puede ocurrir que ciertos trabajadores informales sean contratados por las grandes empresas formales con el fin de reducir sus costos de producción, y de esta manera los primeros se convierten en una precondición para su desarrollo. Wanderley, 2009. 
TABLA 8. UTILIZACIÓN DE LA VIVIENDA PARA TRABAJAR SEGÚN LUGAR DE NACIMIENTO DE LOS MIEMBROS ADULTOS DEL HOGAR. TOTAL DE HOGARES DE LOS BARRIOS EL PORVENIR Y 16 DE JULIO, AÑO 2012. (EN PORCENTAJES)*

\begin{tabular}{llc|c|c}
\hline \multirow{2}{*}{ Nombre del Barrio } & & \multicolumn{2}{c}{ ¿Utiliza algún lugar para trabajar en esta casa? } \\
& & Sí & No & \multicolumn{2}{c}{ Total } \\
\hline \multirow{3}{*}{ El Porvenir } & $\begin{array}{l}\text { Hogar con adultos nacidos en } \\
\text { el campo }\end{array}$ & 21,7 & 78,3 & $100(46)$ \\
\cline { 2 - 5 } & $\begin{array}{l}\text { Hogar sin adultos nacidos en } \\
\text { el campo }\end{array}$ & 66,7 & 33,3 & $100(3)$ \\
\cline { 2 - 5 } & Total & 24,5 & 75,5 & $100(49)$ \\
\hline \multirow{3}{*}{16 de Julio } & $\begin{array}{l}\text { Hogar con adultos nacidos en } \\
\text { el campo }\end{array}$ & 30 & 70 & $100(20)$ \\
\cline { 2 - 5 } & $\begin{array}{l}\text { Hogar sin adultos nacidos en } \\
\text { el campo }\end{array}$ & 20 & 80 & $100(30)$ \\
\cline { 2 - 5 } & Total & 24 & 76 & $100(50)$ \\
\hline
\end{tabular}

* Se eliminaron de los totales aquellos que se encuentran en la categoría "No saben, no contestan".

Fuente: Elaboración propia según encuesta realizada en el año 2012. 


\section{Informalidad e inestabilidad laboral}

Como se planteó, para comprender la existencia de un desarrollo urbano desigual en El Alto es importante analizar la posición de los hogares de migrantes en el mercado de trabajo respecto a la informalidad e inestabilidad laboral. Para lo cual se elaboró una tipología de formalidad/informalidad en función de la definición legal o de protección social ${ }^{74}$. El primer caso distingue a aquellos trabajadores en relación de dependencia que el empleador le descuenta para los aportes jubilatorios, y los trabajadores por cuenta propia ${ }^{75}$ sin empleados a su cargo (no calificados) ${ }^{76}$ que están inscriptos en el Servicio Nacional de Impuestos Internos y realizan sus aportes; y en el segundo, a los que no le realizan los aportes jubilatorios o no están inscriptos en dicho Servicio.

74 Gasparini y Tornarolli, 2009.

75 No se analizaron a los denominados trabajadores por cuenta propia con empleados a su cargo, ya que este trabajo se centra en la informalidad de los trabajadores y no se incluye a los pequeños patrones.

76 La totalidad de los trabajadores por cuenta propia en ambos barrios no son calificados ya que no poseen un titulo terciario o superior. Esto es representativo de la ciudad de El Alto, donde según el Censo 2012, el nivel educativo de la población de 19 años y más se concentra, en primer lugar, en el nivel Secundario $(38,6 \%)$.

138 revista invi № 85 / Noviembre 2015 / Volumen № 30: 111-146
En ambos barrios impera el tipo de inserción informal en el mercado laboral, representando en El Porvenir el 93,8\% del total de jefes de hogar, y en 16 de Julio el 97,7\%. Aunque bajo el gobierno de Evo Morales se derogó el artículo del Decreto Supremo $\mathrm{N}^{\circ} 21060^{77}$ que aludía a la liberalización del mercado laboral, esto no trajo consigo una liquidación del empleo informal y precario. De aquí se desprende el problema estructural de la informalidad laboral en la ciudad de El Alto, y en Bolivia ${ }^{78}$.

Si bien la informalidad laboral de los jefes de hogar es lo que prevalece, puede analizarse la inestabilidad del empleo como un indicador adicional de precariedad y de empobrecimiento de estos mismos sectores sociales (o categorías ocupacionales). Esto último se vincula con los menores ingresos, y la menor disponibilidad de capital en el caso del cuentapropismo, asociado a la inestabilidad ${ }^{79}$. Se distinguen las actividades informales consolidadas y no consolidadas ${ }^{80}$.

77 No obstante, la posterior promulgación del Decreto Supremo $N^{\circ} 861$ que derogó al D. S.N²1060 paradójicamente no se constituyó en una ruptura abrupta con el Decreto de 1985 ya que lo suprimió parcialmente.

78 Según la definición legal, hacia el 2010, el 90\% del conjunto de los trabajadores de Bolivia (los asalariados y los cuentapropistas no calificados) son informales (Tornarolli, Battistón, Gasparini y Gluzmann, 2014).

79 Es importante aclarar que la pregunta que refiere a la inestabilidad laboral también fue medida para los trabajadores por cuenta propia sin empleados a su cargo, aunque la respuesta posee un tinte más subjetivo, es un indicador indirecto de la menor disponibilidad de capital y los bajos recursos que genera su actividad.

80 Rosell y Rojas, 2006; Escobar y Guaygua, 2008. 
TABLA 9. TIPO DE INSERCIÓN EN EL MERCADO LABORAL DE LOS JEFES DE HOGAR (ACTIVOS). TOTAL DE HOGARES DE LOS BARRIOS EL PORVENIR Y 16 DE JULIO, AÑO 2012 (EN PORCENTAJES)*

\begin{tabular}{lcccc}
\hline \multirow{2}{*}{ Nombre del Barrio } & \multicolumn{3}{c}{ Tipo de inserción en el mercado laboral } \\
\cline { 2 - 4 } & Informal & Formal & Total \\
\hline El Porvenir & 93,8 & 6,2 & 100 (48) \\
\hline 16 de Julio & 97,7 & 2,3 & \multirow{2}{*}{100 (44) } \\
\hline
\end{tabular}

* Se eliminaron los casos sin respuesta a las categorías de la encuesta que miden la informalidad laboral, y a los jefes de hogar inactivos. Fuente: Elaboración propia según encuesta realizada en el año 2012

TABLA 10. CALIDAD DE LA OCUPACIÓN DE LOS JEFES DE HOGAR (ACTIVOS). TOTAL DE HOGARES DE EL PORVENIR Y 16 DE JULIO, AÑO 2012 (EN PORCENTAJES)

\begin{tabular}{lc|cc}
\hline \multirow{2}{*}{ Nombre del Barrio } & \multicolumn{2}{c}{ Calidad de la Ocupación } & Total \\
& Permanente & Temporario & 100(48) \\
\hline El Porvenir & 45,8 & 54,2 & $100(40)$ \\
\hline 16 de Julio & 57,5 & 42,5 & (1) \\
\hline
\end{tabular}

Fuente: Elaboración propia según encuesta realizada en el año 2012. 
Como se puede observar en la tabla 10, en El Porvenir, los jefes de hogar se insertan en actividades informales no consolidadas ya que impera la inestabilidad laboral $(54,2 \%)$, mientras en 16 de Julio la estabilidad del empleo (57,5\%). Por consiguiente, la fracción más empobrecida y precarizada de los sectores populares y trabajadores, migrantes de las comunidades rurales, se encuentra en la periferia en un contexto urbano de absoluta precariedad.

En cambio, en el barrio 16 de Julio se concentran los hogares de no migrantes, los cuales se insertan en un hábitat de mayor consolidación urbana (aunque relativa), y en un espacio urbano donde coexiste lo precario y lo no precario. Los jefes de hogar en este barrio se insertan en empleos informales consolidados, lo que implica mayores recursos y/o disponibilidad de capital. En este sentido, puede señalarse que los sectores populares y trabajadores no conforman un estrato social homogéneo sino que se encuentran capas más empobrecidas unas respecto a las otras.

\section{Conclusiones}

La conformación de los dos barrios alteños analizados expresan el proceso de urbanización ${ }^{81}$ de un país con escasos recursos y limitadas políticas públicas, así como también las distintas etapas del crecimiento de El Alto, que fueron parte de la formación metropolitana de la ciudad de La Paz. Entonces, el desarrollo urbano desigual y combinado estudiado se encuentra estrechamente vinculado con este fenómeno de expansión y crecimiento de la mancha urbana.

En este sentido, las desiguales situaciones de los barrios $^{82}$ responden a los distintos momentos de crecimiento urbano alteño que se vinculan con la antigüedad de los mismos, a saber: el barrio periférico El Porvenir ${ }^{83}$ de reciente formación es un área de baja consolidación en expansión, mientras el barrio antiguo 16 de Julio se halla "relativamente" consolidado y en densificación. Cabe preguntarse si esta desigualdad es una muestra del rol

81 Este proceso de urbanización al mismo tiempo conllevó un proceso de consolidación migratoria de la población en el tiempo.

82 Las desiguales situaciones de los barrios respecto a la cobertura de los equipamientos comunitarios, de la infraestructura urbana y de los servicios públicos domiciliarios (y de mantenimiento urbano); así como en relación a la dinámica migratoria y a las prácticas cotidianas de la población.

83 Hipotéticamente es probable que el crecimiento urbano siga en aumento, por lo tanto, que el barrio El Porvenir se densifique y se consolide depende en parte tanto de la dinámica demográfica, de la dinámica urbana como de la presión que pueda ejercer la organización vecinal. 
segregador (indirecto) de las políticas públicas que se adaptan a esta dinámica urbana, ya que las inversiones se concentran en los barrios de mayor densidad poblacional debido a su mayor rentabilidad. A pesar de considerar a la vivienda y al hábitat adecuado como un derecho humano en la Nueva Constitución Política del Estado (2009) se carece de un "Plan Nacional de Vivienda" que apunte al déficit cualitativo, especialmente de las áreas periféricas, que es el principal problema de Bolivia.

Esta investigación cuestiona el discurso académico y oficial hegemónico sobre la presunta homogeneidad de la ciudad de El Alto. Los sectores populares no conforman un estrato social homogéneo, se encuentran capas más empobrecidas vinculadas con su inserción informal no consolidada. Además, la población aymara migrante tampoco se distribuye en forma homogénea en la ciudad, sino que se concentra en la periferia. De este modo, en el barrio 16 de Julio la composición de la población es netamente local (alteña o paceña), aunque pueda ocurrir que haya un porcentaje considerable que sean hijos o nietos de migrantes ${ }^{84}$.

En este trabajo se pudo demostrar que la condición de precariedad residencial de la población del barrio periférico está asociada a la condición

84 Este tema no fue objeto de análisis, lo que podría abordarse en un futuro. migratoria de los adultos del hogar y a un tipo de inserción laboral del considerado jefe de hogar. A su vez, esta situación no se encuentra directamente vinculada con el tipo de inserción en el mercado de vivienda/ tierra (formal/informal). De hecho se demostró que la mera política de regularización de la situación dominial, si no comporta una reestructuración del mercado laboral, no produce la ansiada mejora del hábitat.

También se intentó demostrar el desarrollo urbano desigual y combinado en la ciudad de El Alto, conformada fundamentalmente mediante el loteamiento informal y con importantes niveles de NBI. En este sentido, las áreas céntricas de mayor consolidación y las áreas periféricas no forman parte de una "ciudad dual" sino que son producto del mismo proceso histórico.

Finalmente, bajo la globalización neoliberal y post-neoliberal, pese a las diferencias en cuanto al rol del Estado, que de mero regulador adquirió uno más intervencionista en los ámbitos político, social y económico, la población alteña en general y en mayor medida los hogares de migrantes que se concentran en la periferia de la ciudad, no accedieron aún al derecho a la ciudad: vivir en un hábitat integrado a los servicios, a la infraestructura urbana y a las oportunidades educativas y laborales ${ }^{85}$. Este derecho incluye una

85 Suárez, PNUD, 2009. 
diversidad de derechos, entre ellos el derecho al trabajo adecuado, cuestión negada al conjunto de los trabajadores de El Alto.

\section{Bibliografía}

ABRAM0, Pedro. Producción de las ciudades latinoamericanas: informalidad y mercado del suelo. En: CRAVINO, María Cristina, comp. Repensando la ciudad informal en América Latina. Buenos Aires, Universidad Nacional de General Sarmiento. 2012. P. 199-232. ISBN 978-987-630-139-8.

ALB0, Xavier. El Alto, la vorágine de una ciudad única. [En línea]. The Journal of Latin American and Caribbean Anthropology. 11(2): 329-350, 2006. ISSN 1935-4940. Disponible en: http://dx.doi. org/10.1525/jlca.2006.11.2.329.

ARBONA, Juan Manuel. Eso es ser pobre e indio en este país. Repercusiones urbanas e implicaciones sociales de la discriminación y la exclusión: lecciones de El Alto, Bolivia. En: ZABALA ARGUELLES, María del Carmen, comp. Pobreza, exclusión social y discriminación étnico-racial en América Latina y el Caribe. Bogotá, Siglo del Hombre Editores, CLACSO. 2008. p. 349-372. ISBN 978-958-665-124-0.

BALLIVIAN, Danilo Paz. Estructura agraria boliviana. 3a. ed. La Paz, Plural ediciones. 2009. 194 p. ISBN 978-99954-1-245-6.

CHOQUE QUISPE, María Eugenia y ENRÍQUEZ A., Cecilia, Chacha warmi, imaginarios y vivencias en El Alto. La Paz, Centro de Promoción de la Mujer Gregoria Apaza. 2009. 135 p.

DI VIRGILIO, María Mercedes. Trayectorias residenciales en el área metropolitana de Buenos Aires, Argentina: los componentes de la movilidad residencial. Cadernos IPPUR/UFRJ. 22(2): 37-66, agosto 2008. ISSN 1984-7661.

DO ALTO, Hervé. Cuando el nacionalismo se pone el poncho. Una mirada retrospectiva a la etnicidad y la clase en el movimiento popular boliviano (1957-2007). En: SVAMPA, Maristella, comp. y STEFANONI, Pablo, comp. Bolivia. Memoria, insurgencia y movimientos sociales. Buenos Aires, Editorial El Colectivo. 2007. p. 21-53. ISBN 978-987-23514-7-2.

DUNKERLEY, James. Rebelión en las venas. 2a. ed. La Paz, Plural editores. 2003. 416 p. ISBN 99905-75-19-3.

DURÁN, Jaime; ARIAS, Karen y RODRÍGUEZ, Marcelo. Casa aunque en la punta del cerro. Vivienda y desarrollo de la ciudad de El Alto. La Paz, Fundación PIEB. 2007. 116 p. ISBN 978-99954-32-10-2.

ESCOBAR DE PABÓN, Silvia y GUAYGUA, Germán. Estrategias familiares de trabajo e inserción laboral de los hogares. Buenos Aires, CLACSO. 2008. 144 p. ISBN 978-987-1543-02-1. 
GARCÍA LINERA, Álvaro. La potencia plebeya. Acción colectiva e identidades indígenas, obreras y populares en Bolivia. Buenos Aires, Siglo del Hombre Editores, Clacso. 2008. 416 p. ISBN 978-987-574-273-4.

--- El "capitalismo andino amazónico". [En línea]. Le Monde Diplomatique. 2006. [Fecha de consulta: 29 agosto 2014]. Disponible en: http://www. lemondediplomatique.cl/El-capitalismo-andinoamazonico.html.

GARFÍAS, Sandra y MAZUREK, Hubert. El Alto desde una perspectiva poblacional. La Paz, CODEPOIRD. 2005. 180 p. ISBN 99905-0-884-4.

GASPARINI, Leonardo y TORNAROLLI, Leopoldo. Labor informality in Latin America and the Caribbean: patterns and trends from household survey microdata. Desarrollo y Sociedad. (63): 13-80, junio 2009. ISSN 0120-3584.

GOZÁLVEZ, Bertha. Definición de áreas homogéneas en la ciudad de La Paz. En: CORDOVA, Jorge y ROUX, Jean Claude. Primera reunión nacional de geografía boliviana: actas de la reunión. La Paz, UMSA-ORSTOM. 1996. p. 171-188.

GROISMAN, Fernando y SUÁREZ, Ana Lourdes. Segregación residencial e inserción laboral en el conurbano bonaerense. Población de Buenos Aires. 7(11): 7-28, abril 2010. ISSN 1668-5458.

GUAYGUA, Germán. Identidad colectiva y movilidad social en la ciudad de El Alto. En: GUAYGUA, Germán; PEÑA, Claudia y WALDMANN, Adrián. Nuevas identidades urbanas. Tres miradas desde la cultura y la desigualdad. La Paz, PNUD. 2011. p. 237-318. Cuaderno de futuro 27. ISBN 978-99954-711-6-3.

HARVEY, David. Ciudades rebeldes. Del derecho a la ciudad a la revolución urbana. Madrid, Akal. 2012. 238 p. ISBN 978-84-460-3799-6.

--- El "nuevo" imperialismo: sobre reajustes espaciotemporales y acumulación mediante desposesión (I). Viento Sur. 1(447): 1-26, abril 2004. ISSN 1133-5637.

HERZER, Hilda, org. Con el corazón mirando al sur. Transformaciones en el sur de la ciudad de Buenos Aires. Buenos Aires, Espacio Editorial. 2008. 368 p. Colección desarrollo social y sociedad. ISBN 978-950-802-291-2.

INDABURU QUINTANA, Rafael. Evaluación de la ciudad de El Alto. [en línea]. USAID. 2004. [Fecha de consulta: 1 septiembre 2014]. Disponible en: http://pdf.usaid.gov/pdf_docs/pnadg073.pdf.

JARAMILLO, Samuel y CUERVO, Luis Mauricio. La urbanización latinoamericana. Nuevas perspectivas. Colombia, Escala. 1993. 91 p. Colección Historia y Teoría Latinoamericana v. 3. ISBN 958-9082-74-2.

KLEIN, Herbert. Historia de Bolivia. 3a. ed. La Paz, Librería Editorial Juventud. 2002. 344 p.

MAMANI RAMÍREZ, Pablo. El rugir de las multitudes. La fuerza de los levantamientos indígenas en Bolivia/Qullasuyu. La Paz, Ediciones Yachaywasi. 2004. 161 p. ISBN 99905-0-563-2. 
MAZUREK, Hubert. Lo urbano: la cristalización de lo social y de lo espacial. En: WANDERLEY, Fernanda, coord. Estudios urbanos en la encrucijada de la interdisciplinariedad. La Paz, Plural editores. 2009. p. 27-56. ISBN 978-99954-754-0-6.

NUÑEZ VILLALBA, Javier. La localización de las ciudades de Bolivia y el crecimiento acelerado de la aglomeración urbana paceña. En: ANTEQUERA DURÁN, Nelson y CIELO, Cristina. Ciudad sin fronteras. Multilocalidad urbano rural en Bolivia. La Paz, Ritu Bolivia, Seminario permanente de Reflexioín Interdisciplinar en Temas Urbanos : Fundación PIEB. 2011. p. 41-70. ISBN 978-99954-32-96-6.

PEREIRA MORATÓ, René. Las ciudades bolivianas, ¿cómo entenderlas? Migración y urbanización. En: WANDERLEY, Fernanda, coord. Estudios urbanos en la encrucijada de la interdisciplinariedad. La Paz, Plural editores. 2009. ISBN 978-99954-754-0-6.

PNUD. Aportes para el desarrollo humano en Argentina. Segregación residencial en Argentina. [En línea]. PNUD. 2009. [Fecha de consulta: 29 agosto 2014]. Disponible en: http://www.ar.undp.org/content/ argentina/es/home/library/human_development/ AportesDHArg2.html

PORTES, Alejandro y HALLER, William. La economía informal. Santiago de Chile, CEPAL. 2004. 55 p. Serie Políticas Sociales. ISBN 1564-4162.

PRADILLA COBOS, Emilio. Ensayos sobre el problema de la vivienda en América Latina.
México, Xochimilco, Universidad Autónoma Metropolitana. 1983. 472 p. ISBN 9685974004 Colección Ensayos.

QUISPE ALVARADO, David Carlos; TONCONI MAMANI, Florencia y CANAVIRI MAMANI, Celia. Warmis alteñas en el puesto de la vida: testimonio económico y político de las mujeres del comercio minorista en la ciudad de El Alto. El Alto, Centro de Promoción de la Mujer Gregoria Apaza. 2011. 329 p. ISBN 978-99954-798-3-1.

QUISPE VILLCA, Marco Alberto. De ch'usa marka a jach'a marka: (de pueblo vacío a pueblo grande); pequeñas historias contadas desde el alma misma de El Alto. La Paz, Plural editores. 2004. 147 p. ISBN 99905-75-51-7.

RODRíGUEZ, María Carla; DI VIRGILIO, María Mercedes; Procupez, Valeria; Vio, Marcela; Ostuni, Fernando; Mendoza, Mariana y MORALES, Betsy. Producción social del hábitat y políticas en el Área Metropolitana de Buenos Aires: historia con desencuentros. [En línea]. Buenos Aires, Instituto de Investigaciones Gino Germani Facultad de Ciencias Sociales de la UBA. Febrero, 2007. Documento de trabajo 49. ISBN 978-950-29-09806. [Fecha de consulta: 5 septiembre 2014]. Disponible en: http://lanic.utexas.edu/project/laoap/ iigg/dt49.pdf

ROSELL, Pablo y ROJAS, Bruno. Destino incierto: esperanzas y realidades laborales de la juventud alteña. 2a. ed. La Paz, CEDLA. 2006. 73 p. Serie ciudad y desarrollo 6. 
SALAZAR ANTEQUERA, Gonzalo. La vivienda social en Bolivia. La Paz, Vamy Ediciones. 2001. 122 p.

TOPALOV, Christian. La urbanización capitalista México, Edicol. 1979. 186 p. ISBN 9684080263.

TORNAROLLI, Leopoldo; BATTISTÓN, Diego; GASPARINI, Leonardo y GLUZMANN, Pablo. Exploring trends in labor informality in Latin America, 1990-2010. [En línea]. CEDLAS. 2014. [Fecha de consulta: 1 septiembre 2014]. Disponible en: http://cedlas.econo.unlp.edu.ar/ esp/areas-documentos.php?idA=3

TORRICO ADAD, Aida. La Paz: proceso urbano, centro histórico y espacio social. La Paz, Universidad Franz Tamayo. 2004. 80 p.
WANDERLEY, Fernanda. Crecimiento, empleo y bienestar social ¿Por qué Bolivia es tan desigual? La Paz, CIDES-UMSA, Plural Editores. 2009. 213 p. ISBN 978-99954-754-2-0.

YUJNOVSKY, Oscar. Claves políticas del problema habitacional argentino 1955-81. Buenos Aires, Grupo Editor Latinoamericano. 1984. 416 p. ISBN 978-950-9432-00-0. 